\title{
Structure, Function, and Regulation of Tartrate-Resistant Acid Phosphatase
}

\author{
G. W. ODDIE, G. SCHENK, N. Z. ANGEL, N. WALSH, L. W. GUDDAT, J. DE JERSEY, \\ A. I. CASSADY, S. E. HAMILTON, and D. A. HUME
}

Department of Biochemistry, Department of Microbiology and Parasitology and Institute for Molecular Bioscience, University of Queensland, Australia

\section{Introduction: Biochemistry of Tartrate-Resistant Acid Phosphatase Enzymes}

The tartrate-resistant acid phosphatases (TRAPs) are a class of metalloenzymes that catalyze the hydrolysis of various phosphate esters and anhydrides under acidic reaction conditions. Because the bound metal ions confer an intense color on these enzymes they are also known as purple acid phosphatases (PAPs). Resistance to inhibition by high concentrations of the competitive inhibitor $\mathrm{L}+$ tartrate distinguishes TRAP from acid phosphatases of lysosomal or prostatic origin present in many mammalian cells and tissues. ${ }^{58}$

TRAP enzymes have been isolated from many mammalian sources, including: bovine ${ }^{24,89}$ and rat spleen ${ }^{49}$; the spleens of patients affected with hairy cell leukemia ${ }^{63}$ and Gaucher's disease $^{99}$; human ${ }^{2,53}$ and rat bone ${ }^{3}$; and human lungs ${ }^{28}$ and placenta. ${ }^{64}$ The TRAP purified from porcine allantoic fluid, which is also known as uteroferrin, was originally recognized as an abundant basic protein in uterine secretions induced by progesterone. ${ }^{21}$ The catalytic mechanism, structure, and properties of the iron center of porcine TRAP have been studied extensively by our group. ${ }^{10,18,61,62,122}$

Mammalian isolated TRAP enzymes all have similar physical properties, including a molecular weight of about $35 \mathrm{kDa}$, a basic isoelectric point (pI 7.6-9.5), and optimal enzyme activity at an acidic $\mathrm{pH}$. The enzyme can be isolated as a single chain polypeptide, but a dimeric nicked form arises from posttranslational cleavage of the single chain enzyme. Cleavage occurs in an exposed loop that is conserved in all mammalian TRAP enzymes and leads to an increase in $V_{\max } / k_{\mathrm{cat}}$ of the enzyme by an unknown mechanism. ${ }^{29,51,59,80,89}$ Several proteolytic enzymes are able to cleave the exposed loop, but only the cysteine proteinases papain and cathepsin B have been able to cause activation among several tested. Ljusberg et al. ${ }^{75}$ put forth the view that TRAP, like several other hydrolases, is synthesized as a relatively inactive proenzyme, and cleavage is the physiological mechanism of proenzyme activation in osteoclasts.

Mammalian TRAP enzymes are glycoproteins and, like most lysosomal enzymes, possess the mannose-6-phosphate lysosomal targeting sequence, which must presumably be cleaved or modified to permit secretion. TRAP isolated from allantoic fluid of the pig showed a single, unphosphorylated, high-mannose-type

Address for correspondence and reprints: Dr. David A. Hume, Department of Immunology, University of Washington, 1959 Pacific Street NE, H-574, Box 357650, Seattle, WA 98195-7650. E-mail: director@cmcb.uq.edu.au oligosaccharide composed of five or six mannose residues and two $\mathrm{N}$-acetylglucosamine residues. ${ }^{8,98}$ In contrast, recombinant porcine TRAP secreted by Chinese hamster ovary $(\mathrm{CHO})$ cells possessed N-linked, high-mannose oligosaccharide chains that were phosphorylated and could not be dephosphorylated by alkaline phosphatase treatment in vitro. This suggests that the uteroferrin oligosaccharide phosphates were not exposed, perhaps as a result of blocking by an $N$-acetylglucosamine residue. ${ }^{74}$ The glycoprotein structure of human bone TRAP was analyzed by lectin binding and, in agreement with the prior analysis of native uteroferrin, contained only N-linked high-mannose carbohydrates, ${ }^{41}$ implying that the native secreted protein is normally dephosphorylated. Analysis of TRAP activity present in electrophoretically separated human serum revealed two isoforms, termed $5 \mathrm{a}$ and $5 \mathrm{~b}$, with each isoform having a different $\mathrm{pH}$ optimum (5a: $\mathrm{pH} 4.9$; 5b: $\mathrm{pH}$ 5.5-6.0). ${ }^{69}$ The carbohydrate content of the isoforms also differed with only isoform 5a containing sialic acid. ${ }^{68}$

TRAP contains two iron atoms at its active site, and the intense purple color of the enzyme results from a tyrosinate $\mathrm{Fe}$ (III) charge transfer. Reduction of the active site binuclear center to a mixed valency $\mathrm{Fe}(\mathrm{III})-\mathrm{Fe}$ (II) form is required for activation and this corresponds to a shift in color from purple to pink. Further reduction or the presence of iron chelators can lead to reversible inactivation and formation of a colorless form of the enzyme. ${ }^{44}$ The enzyme is also inhibited noncompetitively by incubation with vanadate ${ }^{22}$ or simply following more extended incubation at $37^{\circ} \mathrm{C}{ }^{44}$ The latter case at least, produced a "yellowish" form of the enzyme. ${ }^{44}$ TRAP may become irreversibly inactivated by oxidation in the presence of ascorbate. ${ }^{9}$ The recent availability of monoclonal antibodies against TRAP $^{20,41,43,44,51,57}$ has permitted the identification of an inactivated "yellowish" form of the enzyme as the major form in the circulation. ${ }^{44}$

\section{Enzyme Mechanism and Conservation of TRAP-like Enzymes from Nonmammalian Sources}

Purple acid phosphatase from the red kidney (RKBPAP) was the first member of this family for which a crystal structure became available. ${ }^{116}$ RKBPAP is a larger enzyme than the mammalian PAPs (111 kDa dimer) and contains $\mathrm{Fe}(\mathrm{III})-\mathrm{Zn}$ (II) at the active site instead of $\mathrm{Fe}(\mathrm{III})-\mathrm{Fe}(\mathrm{II})$. Only $3.1 \AA$ separate the two metal ions at the active site of RKBPAP and the amino acid residues that provide the metal ligands are conserved across all known members of the PAP family. The octahedral coordination of the metals was presumed to be completed by a bridging hydroxo group, a hydroxyl group coordinated to $\mathrm{Fe}(\mathrm{III})$, and a water 


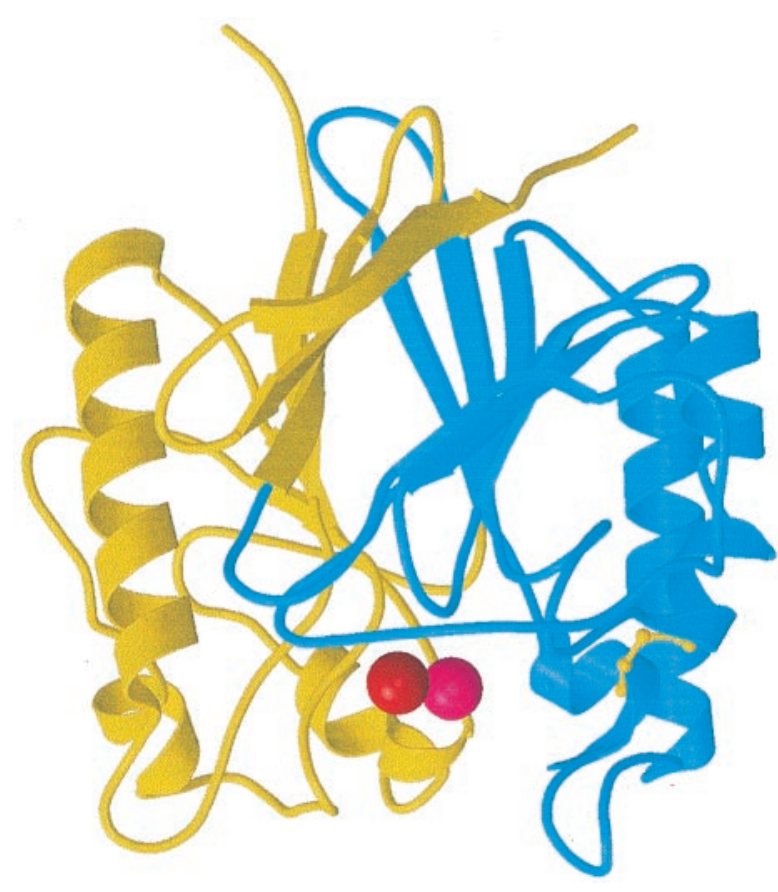

Figure 1. Crystal structure of porcine TRAP. ${ }^{39}$ The Fe(III) atom is shown as a purple sphere, and the redox-active $\mathrm{Fe}$ atom as a red sphere. The disulfide bond between Cys 141 and Cys 2000 is shown as a yellow ball-and-stick model. To highlight the pseudo-symmetry of the porcine TRAP molecule one half (residues 1-115 and 270-303) is colored yellow and the other half (residues 116-269) is blue.

molecule coordinated to $\mathrm{Zn}(\mathrm{II})$. These ligands were not visible on the electron density map. A reaction mechanism of RKBPAP was proposed in which initial binding of the phosphate ester to $\mathrm{Zn}$ (II) displaces the bound $\mathrm{H}_{2} \mathrm{O}$ followed by displacement of the alcoholic product by an Fe(III)-bound hydroxide ion. ${ }^{66}$

Sequence alignment of RKBPAP with porcine TRAP suggested that RKBPAP is a good model for the structure and mechanism of other acid phosphatases. ${ }^{67} \mathrm{We}$ recently confirmed this overall prediction with solution of the crystal structure of the porcine enzyme at $1.5 \AA$ resolution ${ }^{39}$ (Brookhaven Database, Access Code 1ute). Together with other groups we produced substantial amounts of recombinant mouse, rat, and human TRAP in baculovirus expression systems. ${ }^{29,51,80}$ Although preliminary crystallization appeared promising there was a considerable delay between the availability of recombinant enzyme and production of crystals of sufficient size and quality to permit structure determination. In our studies, progress was assisted greatly by the availability of abundant native porcine enzyme from allantoic fluid and was expedited by prior knowledge that it was possible to produce a very stable oxidized enzyme phosphate complex. ${ }^{61}$ The crystal structure shown in Figure 1 reveals a symmetry that was less evident in the plant enzyme structure, and suggests that the binuclear iron center could have evolved from the combination of two mononuclear metal-ion-binding sites. The high-resolution structure revealed strong electron density between the two irons in the active site, indicating the presence of a bridging oxo/hydroxo group. Coincident solution of the structure of recombinant rat TRAP at $2.3 \AA$ resolution by another group of investigators confirmed the overall conclusions from the porcine structure. ${ }^{119}$

The combination of structural and mechanistic studies provides insight into the catalytic mechanism of PAPs. In the initial step, the phosphate group of the substrate is coordinated to the divalent metal ion. Stopped-flow measurements on the pig enzyme have indicated a rapid binding of phosphate to $\mathrm{Fe}(\mathrm{II}){ }^{6}$ suggesting that this step is not rate-limiting. Formation of the enzyme-substrate complex is followed by a nucleophilic attack on the phosphorus leading to the release of the product alcohol. The nature of the attacking group remains uncertain. Three possible candidates have been proposed: (i) a terminal Fe(III)bound hydroxide $^{66}$; (ii) a bridging hydroxide ${ }^{120}$; or (iii) a hydroxide residing in the second coordination sphere of $\mathrm{Fe}(\mathrm{III}){ }^{81}$ The absence of burst kinetics in bovine TRAP indicates that the nucleophilic attack is probably rate-limiting. ${ }^{82}$ In the final step of catalysis the metal-bound phosphate group is released. Metal replacement studies have indicated that the $k_{\text {cat }}$ value of the hydrolysis is not affected by the nature of the trivalent metal ion. ${ }^{81}$ This observation indicates that phosphate release is not rate-limiting and suggests that no ligand substitution reaction takes place at the trivalent site. The latter conclusion argues against the proposition that the nucleophile is located in the first coordination sphere of the binuclear center (see earlier).

With the rapid accumulation of DNA sequence information from a diversity of organisms, sequences of cDNAs from many different sources have become available. Alignment of some known TRAP-like sequences is shown in Table 1. TRAP-like enzymes are found in organisms ranging from Aspergillus sp., certain Mycobacteria, through primitive animals to higher plants and mammals. The presence of related enzymes in intracellular pathogens that infect macrophages could be related to virulence. ${ }^{96}$ Otherwise, a detailed search of the complete Saccharomyces genome, completed Drosophila sequences, and several bacterial genomes reveals no genes with conserved metal ionbinding motifs. ${ }^{105}$ This suggests either that the function(s) performed by TRAP are not absolutely required for all eukaryotic cells, or that a nonpurple enzyme that is not detected with the search motif performs the same function. In prokaryotes, TRAP enzymes may not be required because these organisms lack an acidic subcellular compartment in which such enzymes would be active. TRAP enzymes are found in invertebrates such as $C$. elegans, so the role TRAP carries out in animals is not restricted to those creatures with bones. The alignment defines a signature motif that can be used to identify new members of the gene family, as they become evident in sequence databases. Among the genes shown in Table 1 is a newly discovered class of plant enzymes more closely resembling mammalian enzymes in terms of signature motif and size ${ }^{105}$ - the archetype and first discovered being from the Easter lily. Purification and characterization of these mammalian-type plant enzymes is proceeding in our laboratory. The function of purple plant phosphatases is unknown, the only real clue being the fact that they are inducible in some plants by phosphate deprivation. ${ }^{25,71}$ It is possible that elucidation of their function may give insight into the role of TRAP in mammals. Novel structural features of recently discovered plant TRAP enzymes include membrane localization via a GPI anchor in an enzyme purified from duckweed. ${ }^{85}$

\section{Substrate Specificity of TRAP}

TRAP can catalyze the hydrolysis of a wide range of phosphate monoesters and anhydrides, including the widely used substrates $\beta$-umbelliferylphosphate, $p$-nitrophenolphosphate, and pyrophosphate, with $K_{\mathrm{m}}$ values at $\mathrm{pH} 4.9$ in the millimolar range. ${ }^{80}$ In our studies, ${ }^{86}$ and those of others, ${ }^{44}$ pig, mouse, and human enzymes had specific protein tyrosine phosphatase activity. With phosphotyrosylpeptide substrates, the apparent $K_{\mathrm{m}}$ was decreased to the micromolar range at $\mathrm{pH} 4.9$ by flanking charged amino acids and by a large hydrophobic group (Fmoc) attached to the amino terminus of the peptide sub- 
Table 1. Conserved sequences in plant, animal, and microbial tartrate-resistant acid phosphatases (TRAPs) ${ }^{\mathrm{a}}$

\begin{tabular}{|c|c|c|c|c|c|c|c|c|c|c|c|c|}
\hline & Source & 1 & & 2 & & 3 & & 4 & & 5 & Length & Accession \\
\hline \multirow[t]{7}{*}{ Animals } & Human & GDWG & 34 & GDNFY & 34 & GNHD & 87 & VAGH & 33 & GHDH & 325 & P13686 \\
\hline & Mouse & GDWG & 34 & GDNFY & 34 & GNHD & 89 & VAGH & 33 & GHDH & 327 & Q05117 \\
\hline & Rat & GDWG & 34 & GDNFY & 34 & GNHD & 89 & VAGH & 33 & GHDH & 327 & P29288 \\
\hline & Pig & GDWG & 34 & GDNFY & 34 & GNHD & 89 & VAGH & 33 & GHDH & 338 & P09889 \\
\hline & Cow $^{b}$ & GDWG & -- & GDNFY & -- & GNHD & -- & VAGH & 33 & GHDH & - & Not available \\
\hline & Zebrafish $^{\mathrm{c}}$ & GDWG & 34 & GDNFY & 33 & GNHD & & ---- & & ---- & - & AI415792 \\
\hline & C. elegans & GDTG & 33 & GDNIY & 33 & GNHD & 98 & ISGH & 32 & GHDH & 382 & Z81494 \\
\hline \multirow[t]{5}{*}{ Plants (A) } & Easter lily & GDWG & 29 & GDNFY & 33 & GNHD & 89 & VGHH & 33 & GHDH & 329 & Not available \\
\hline & A. thaliana & GDWG & 29 & GDNFY & 33 & GNHD & 89 & VVGH & 33 & GHDH & 315 & AF200827 \\
\hline & Sweet potato & GDWG & 29 & GDNFY & 33 & GNHD & 89 & VIGH & 33 & GHDH & 313 & AF236107 \\
\hline & Soybean & GDWG & 29 & GDNFY & 33 & GNHD & 89 & VIGH & 33 & GHDH & 333 & AF236108 \\
\hline & Red kidney bean & GDWG & 29 & GDNFY & 33 & GNHD & 89 & VVGH & 33 & GHDH & 332 & AF236109 \\
\hline \multirow[t]{4}{*}{ Plant (B) } & A. thaliana & GDLG & 25 & GDLSY & 32 & GNHE & 79 & VLVH & 35 & GHVH & 469 & Q38924 \\
\hline & Sweet potato & GDIG & 25 & GDLSY & 32 & GNHE & 79 & VLVH & 35 & GHVH & 473 & AF200825 \\
\hline & Soybean & GDLG & 25 & GDLSY & 32 & GNHE & 79 & VLMH & 35 & GHVH & 464 & AF200824 \\
\hline & Red kidney bean & GDLG & 25 & GDLSY & 32 & GNHE & 79 & VLMH & 35 & GHVH & 459 & P80366 \\
\hline \multirow[t]{3}{*}{ Microorganisms } & Aspergillus sp. & NDMG & 25 & GDLSY & 84 & GBHE & 151 & VMSH & 33 & GHIH & 614 & $\mathrm{U} 18554^{\mathrm{d}}$ \\
\hline & Mycobacteria & GDQS & 40 & GDLCY & 31 & GNHE & 89 & VCMH & 35 & GHEH & 529 & $\mathrm{Z} 77724^{\mathrm{e}}$ \\
\hline & Synechocystis sp. & GDIA & 38 & GDNQY & 27 & GNHE & 72 & AYWH & 32 & GHDH & 326 & D90900 ${ }^{f}$ \\
\hline
\end{tabular}

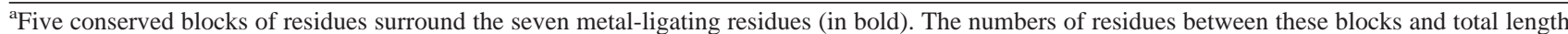
are indicated. Note the clear distinction between the small (A) and large (B) forms of enzyme in plants.

${ }^{b}$ Determined by amino acid sequencing (incomplete).

${ }^{\mathrm{c} O n l y}$ partial sequence available.

${ }^{\mathrm{d}}$ Sequence from A. ficuum.

'Sequence from M. tuberculosis.

${ }^{\mathrm{f}}$ Sequence from Synechocystis 6803.

strate. ${ }^{86}$ These findings suggest that TRAP could have a much greater degree of substrate specificity than previously envisaged, and also indicate that specific active-site antagonists are likely to be possible. Indeed, a series of noncleavable phosphotyrosine analogs of the active peptide substrates were found to be inhibitors, with $K_{\mathrm{i}}$ values at $\mathrm{pH} 4.9$ in the micromolar range (unpublished). The $K_{\mathrm{i}}$ values for these inhibitors were reduced still further at $\mathrm{pH}$ 3.3. This is lower than is normally used in TRAP assays, but the enzyme is actually a more efficient catalyst at this $\mathrm{pH}^{80}$ There is no direct evidence that such a low $\mathrm{pH}$ is attained in the resorptive vacuole of osteoclasts, which has been measured directly by micropuncture $^{32}$ and microelectrode ${ }^{112}$ to be approximately $\mathrm{pH}$ 5. Osteoclasts possess a high-activity adenosine triphosphate (ATP)-dependent proton pump, which is absolutely required for normal bone resorption. ${ }^{73}$ With vectorial secretion of large numbers of protons, the local $\mathrm{pH}$ may be much lower than is evident from bulk-phase measurements with pH-sensitive dyes. ${ }^{56}$ The kidney bean enzyme was also shown to be susceptible to $\mathrm{pH}$-dependent inhibition by the same peptide inhibitors (unpublished), supporting the view that it provides a useful model for the mammalian enzyme. Others have reported on the identification of a series of hydroxynaphthalene phosphonate inhibitors of TRAP with $K_{\mathrm{i}}$ values in the micromolar range, which further supports the view that the enzyme is a viable target for active-site antagonists. ${ }^{110}$

A separate class of substrates for TRAP may be sugar phosphates, possibly in the specific context of glycoproteins. Bresciani and von Figura ${ }^{16}$ provided evidence that TRAP is a major enzyme responsible for hydrolysis of phosphate from the mannose-6-phosphate targeting sequence attached to lysosomal enzymes. The physiological importance of this finding is difficult to assess given the high levels of enzyme activity that were required to observe hydrolysis of mannose-6-phosphate.

\section{Control of TRAP Gene Expression}

\section{Gene Structure and Transcription Control}

In contrast to most plants studied, Southern blot experiments on human, ${ }^{76}$ pig, ${ }^{74}$ and mouse ${ }^{19}$ have detected a single gene, and no related sequences exist in any mammalian EST databases. The human TRAP gene is located on chromosome 19 (19p13.2$13.3)^{70,76}$ and in the syntenic region on mouse chromosome $9 .{ }^{38}$ The overall intron-exon structure of the mouse and human TRAP genes is conserved; they contain five exons with the ATG ("start") codon at the beginning of exon $2 .{ }^{19,34}$ The axis of symmetry of the protein structure lies at the boundary between the exons in the mouse and human genes, which suggests that a gene duplication event may have occurred during the evolution of the TRAP gene. Transcription gives rise to a $1.5 \mathrm{~kb}$ mRNA with an open reading frame of 969-975 bp encoding a 323-325 amino acid protein. ${ }^{19,34}$ The porcine gene is quite different in intron-exon structure with only three exons. ${ }^{19}$

\section{TRAP Expression in Osteoclasts}

The promoter of the TRAP gene, flanking the noncoding exon 1, has been characterized in the human and mouse genes. The sequences of the mouse and human proximal promoters are aligned in Figure 2. Several contradictory locations with regard to the transcription start sites in mouse and human cell lines have been reported, ${ }^{19,95}$ including a possible initiation within the first intron. ${ }^{93}$ We have not been able to detect any transcripts initiating within the first intron in macrophages or osteoclasts by reverse transcription-polymerase chain reaction (RT-PCR) or RNase protection, but uncharacterized elements within the intron are absolutely required for maximal activity of the upstream promoter in transfected RAW264 cells (A.I.C., unpublished observations). Recently, we revisited the issue of transcription 
PU.1

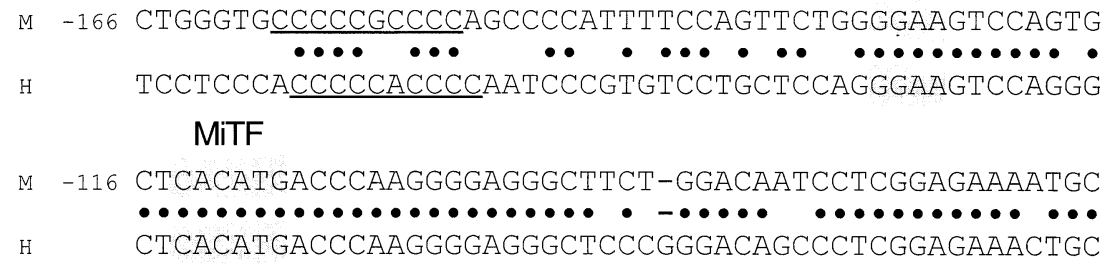

TATA

м -67 ATCATCTTTCCCAATGATGCACTTCTGCCCCAGAGAMMAMAGACTCGGTG

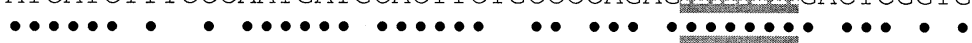

H ATCATCCTCACTAATGATCCACTTCCTCCTCAGGGANMA곡GTCAGGG

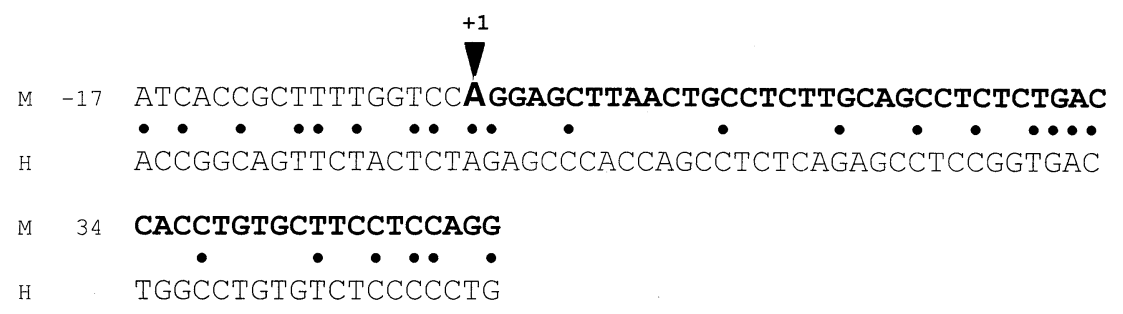

Figure 2. An alignment of the sequences of the murine and human TRAP proximal promoters. The proximal $5^{\prime}$ flanking region of the mouse and human TRAP genes are aligned and sequence identity is marked with a bullet. The variant TATA box is boxed with white text; the osteoclast transcription start point, as determined by $5^{\prime}$-RACE, is marked; the murine exon 1 sequence is shown in bold; the PU.1 binding site and the MiTF binding site are boxed. Candidate $\mathrm{Sp} 1$ sites are underlined.

initiation using purified mouse osteoclasts, which express the highest levels of TRAP mRNA compared with many murine tumor cell lines, all of which express TRAP mRNA at detectable levels. The data indicate that osteoclasts initiate transcription at a single point, downstream of a variant TATA-like element that is conserved between mouse and human, whereas nonosteoclasts initiate transcription from a cluster of sites up to $100 \mathrm{bp}$ upstream (Figure 2). ${ }^{19}$ The same TATA variant (AATAAA) is found upstream of the transcription start site of another osteoclastspecific gene, cathepsin K. ${ }^{72}$ The results indicate that the gene is controlled separately by a typical "house keeping"-type promoter-driving expression in most cells, and a more active TATAcontaining promoter used to direct high-level expression in osteoclasts and probably also in subsets of macrophages. There is relatively little sequence conservation upstream of the proximal promoter region between mouse and human. ${ }^{94}$ Within the conserved region, there are multiple purine-rich elements containing the GGAA core required for recognition by members of the Ets transcription factor family. Ets family transcription factors, particularly the macrophage-specific factor PU.1, have been ascribed in control of many macrophage-specific genes. ${ }^{90,100,101}$ Targeted disruption of the PU.1 gene also causes osteopetrosis and failure of the osteoclast differentiation. ${ }^{117}$ In keeping with such a role, we found that the TRAP promoter can be transactivated in transfections of the macrophage cell line RAW264 by both PU.1 and Ets-2, and that the former factor acts through the conserved Ets element highlighted in Figure 2 (unpublished data). Immediately $5^{\prime}$ of this element there is an E-box motif (CAnnTG), which we have found is a functional response element for the microphthalmia transcription factor (MiTF). ${ }^{77} \mathrm{Mu}-$ tations in the MiTF gene cause osteoclast functional deficiencies $^{115,121}$ such as selective downmodulation of both TRAP mRNA expression and TRAP promoter activity in culture-derived osteoclasts. ${ }^{77}$ MiTF could interact with PU.1 bound to the adjacent site, because the factors can bind directly to each other. ${ }^{104}$ Reddy et al. ${ }^{95}$ noted the presence of multiple binding sites for the transcription factor C/EBP $\beta$ (NF-IL6) in the mouse promoter, a finding of particular interest given the abundant evidence of the effects of interleukin-6 (IL-6)-type cytokines in osteoclastic differentiation and function. ${ }^{79} \mathrm{We}$ found that C/EBP $\beta$ trans-activates the TRAP promoter in transiently transfected RAW264 macrophages (A.I.C. and D.A.H., unpublished observations) although the cis-acting elements involved have not been located.

\section{TRAP Expression at Extraskeletal Sites}

The TRAP from porcine uterus (uteroferrin) may contribute to iron transport and metabolism. ${ }^{17}$ The pig has a noninvasive epitheliochorial placenta, so this precise mode of iron transport is unique to this class of mammals. Nevertheless, we have recently discovered that both TRAP mRNA and protein are present at very high levels in the earliest identifiable invasive trophoblasts in the hemochorial placenta of the mouse (N.W., unpublished observations). The enzyme was purified from human placenta, ${ }^{64}$ so the function and regulation defined in the pig could be partly conserved in other mammals despite the differences in placental architecture. The possibility that TRAP from other tissues is involved in iron transport or storage has led several groups to examine the regulatory influence of intracellular iron on TRAP expression. Decreased levels of TRAP mRNA, resulting from either decreased transcription or increased degradation, have been observed in human peripheral mononuclear cells treated with desferrioxamine, a potent iron-chelating agent. ${ }^{1,12}$ In addition, TRAP promoters of both species have been reported to be regulated by iron in some cell lines, 1,12,92 although we have not been able to reproduce this finding in the murine macrophage line RAW264 (A.I.C., unpublished observations). Reddy et al. ${ }^{91}$ reported that mouse TRAP promoter can be downmodulated by hemin, and characterized the responsive element, GAGGC. Recently, Fleckenstein et al. ${ }^{35}$ analyzed iron responsiveness in the human TRAP promoter and confirmed that GAGGC tandem repeat sequences represent hemin-responsive elements. Regulation by iron would be consistent with the involvement of a 
redox-sensitive loop in TRAP regulation, which is relevant to the roles of oxidants in bone resorption. It is not clear whether iron or hemin regulation occurs in osteoclasts in vivo, nor whether this contributes to the regulation of bone resorption.

During embryonic development of the mouse, TRAP mRNA has been detected by whole-mount in situ hybridization in trophoblasts, and at low levels in hepatic parenchymal cells, but nowhere else until osteogenesis commenced (N.A., N.W., and D.A.H., unpublished observations). As bones start to develop, TRAP mRNA is detectable on unidentified cells associated with early stages of endochondral ossification, later becoming progressively restricted to mononuclear and multinuclear cells that coexpress other markers of osteoclasts. ${ }^{58}$ There is a detailed report on the development expression of TRAP in cells associated with early stages of tooth formation in the mouse, ${ }^{103}$ with TRAP-expressing cells appearing by E12, around bud-stage molar teeth. Aside from intensely stained osteoclasts, TRAP has been detected at high levels in the dental follicle and dental pilla in developing molar teeth. ${ }^{58} \mathrm{~A}$ separate study documented the increase in TRAP mRNA in embryonic rat calvariae from E5 to E20. ${ }^{30}$

Within adult tissues, the cellular sites of TRAP expression have been difficult to determine with confidence, because the histochemical assay is not definitive for TRAP when used at the limits of sensitivity. Angel et al. ${ }^{6}$ and Hayman et al. ${ }^{50}$ analyzed TRAP in adult mouse tissues. Northern blot detected TRAP mRNA in spleen, thymus, liver, lung, skin, kidney, stomach, and small intestines, whereas transcripts were absent from testis, brain, heart, and skeletal muscle. A combination of in situ hybridization, immunohistochemical staining, and TRAP-activity staining of tissue sections established the nature of the expressing cells. ${ }^{49}$ In bone, osteoclasts were strongly TRAPpositive, but chondrocytes within the femoral metaphysis also expressed high levels of mRNA. Overall, results have shown that, apart from macrophages and osteoclasts, TRAP is selectively expressed in Langerhans cells/dendritic cells, and in a number of other cell types of nonhematopoietic origin, including selected chondrocytes, alveolar cells, renal tubular cells, and some hepatic parenchymal cells. These abundant nonhematopoietic cells probably contribute a significant proportion of the total activity/mRNA levels in the major organs studied.

We have made transgenic mice overexpressing TRAP from its own promoter. ${ }^{5}$ The transgenes elicited a copynumber-dependent increase in both mRNA and protein levels in all tissues. Apart from osteoclasts, tissue macrophages, particularly alveolar and splenic macrophages, expressed abundant TRAP protein that was elevated further in the transgenic animals. Among nonmembers of the mononuclear phagocyte system, hepatic parenchymal cells and renal glomerular cells (probably mesangial cells) constitutively expressed detectable TRAP enzyme activity, increasing in a graded fashion with increased transgene copynumber. With the exception of glomerular mesangial expression, which is clear in both wild-type and transgenic animals, the patterns of expression were similar to those observed by Hayman et al. ${ }^{49}$ Independently, a TRAP promoter transgene driving the src protooncogene has also been shown to target expression to liver and kidney. ${ }^{109}$ The generation of TRAP transgenic mice expressing the SV40 large T antigen, with or without the $b c l$-XL antiapoptotic gene, did not transform cells outside the osteoclast lineage. ${ }^{14,54}$ The TRAP promoter has also been used to target overexpression of the c-fos gene to osteoclasts to generate a mouse model with some characteristics of Paget's disease. ${ }^{11}$

Although Langerhans cells in the skin express TRAP, ${ }^{49}$ the gene is also expressed in keratinocytes, and was shown to be elevated in the transgenic animals. ${ }^{6}$ The enzyme has been local- ized to keratohyalin granules in the granular layer and cornified cells in the lower part of the stratum corneum, where it was considered an important phosphoprotein phosphatase. ${ }^{88}$ The reported detection of TRAP activity in the urothelium ${ }^{106}$ suggests that expression of TRAP in cornified epithelium also occurs in humans. TRAP expression in all these sites outside the mononuclear phagocyte system could be simply an indication of high levels of lysosomal activity, or the enzyme could have a specific function that has not yet been determined. No overt defect in any organ other than bone has been detected in TRAP null mice, or in our TRAP overexpressing mice, but without knowing the physiological substrate(s) the nature of such a defect is impossible to predict. Furthermore, some functions of TRAP might be carried by an unrelated enzyme, lysosomal acid phosphatase.

\section{Function of TRAP in Osteoclastic Bone Resorption}

\section{Correlation Between TRAP Activity and Bone Resorption}

By far the greatest interest in the biochemistry of mammalian TRAP relates to its use as a marker for osteoclasts, the cells that resorb bone. The relative specificity of TRAP as an osteoclast marker, its proposed involvement in the resorptive process, and its abundance have suggested that it could be used as a serum marker for bone resorptive activity in pathological states such as osteoporosis. Measurement of serum enzyme activity was confounded by the difficulty of excluding other phosphatases. After an initial enzyme capture assay using antibodies against the porcine enzyme ${ }^{27}$ was used, several groups have developed monoclonal antibodies and enzyme-linked immunosorbent assays (ELISA). ${ }^{20,45-47,51,57}$ In all of these studies there was evidence of elevation of total immunoreactive TRAP in a range of states where osteoclastic activity is elevated, including growing children and postmenopausal women, as well as in Gaucher's and Paget's diseases. Serum TRAP however, was shown to be a poor indicator of bone turnover in response to antiresorptive therapy. ${ }^{48}$ Brehme et al. ${ }^{15}$ noted that much of the TRAP in the circulation forms inactive complexes with the proteinase inhibitor $\alpha 2$-macroglobulin, which may confound the use of TRAP as a marker of bone turnover. Recently, a new serum TRAP assay has been developed that combines enzyme capture with the monoclonal antibody $\mathrm{O} 1 \mathrm{~A}$ and isoform $5 \mathrm{~b}$-specific assay conditions. ${ }^{42}$ This assay indicates that the TRAP $5 b$ isoform is osteoclastic in origin, whereas the 5a isoform is nonosteoclastic and that isoform $5 \mathrm{~b}$ does in fact provide an indicative marker of osteoclastic resorptive activity. ${ }^{42}$

\section{Requirement for TRAP Activity in Osteoclastic Bone Resorption}

The most direct in vitro evidence supporting a role for TRAP in bone resorption has come from osteoclasts cultured on cortical bone slices. Addition of anti-TRAP antibodies reduced the in vitro resorption of bone, ${ }^{84,123}$ an observation we have reproduced using antiserum raised against recombinant murine TRAP (A.I.C., unpublished observations). Addition of bisphosphonate drugs or molybdate to the culture medium was also found to reduce both TRAP activity and bone resorption. ${ }^{84}$ In the somewhat more complex mouse calvarial calcium-release assay, hydroxynaphthalene-phosphonate inhibitors of TRAP also inhibited bone resorption. ${ }^{110}$

Mice with even a heterozygous null mutation introduced into the TRAP gene showed evidence of mild osteopetrosis, which was presumed to be due to defective osteoclastic remodeling activity. ${ }^{52}$ Homozygous TRAP-deficient mice also exhibited abnormal endochondral ossification, which probably reflects the 
high expression of TRAP in chondroclasts at the chondro-osseus boundary during development, ${ }^{87}$ and indicates that TRAP is required for normal mineralization of developing bone as well as for maintaining adult bone integrity through continual remodeling.

As noted earlier, we produced transgenic animals in which tissue-specific overexpression of the TRAP gene was observed in the multiple cell lineages that normally express the gene, including osteoclasts. The animals were mildly osteoporotic, with decreased density of trabeculae with the bone space in long bones, but examination of the rate of bone formation and other indices of osteoblast activity has shown that compensation for increased osteoclast activity occurs through an increase in bone mineralization rate. ${ }^{5} \mathrm{By}$ analogy, the TRAP knockout mouse almost certainly ameliorates the potential phenotypic effects of the mutation and consequent osteoclast defect by decreasing the rate of mineralization and/or increasing the number of osteoclasts to compensate for their lack of function. To some extent, compensation also occurs through the ability of lysosomal acid phosphatase to substitute for TRAP. In contrast to the TRAP knockout, targeted disruption of lysosomal acid phosphatase causes a lysosomal storage disease, ${ }^{102}$ together with minor bone abnormalities. The double knockout in which both genes are mutated was claimed to have a more severe osteopetrotic phenotype, ${ }^{102}$ but the data have not been published. The combined evidence from regulation, inhibition, and transgenic studies indicates that TRAP is a "rate-limiting" enzyme in bone resorption, but overexpression or absence of the gene during development can be partly compensated by homeostatic processes. It must be recognized that the transgenic animal data do not argue against TRAP as a drug target. Currently, we have no information on the effects of specific TRAP inhibitors on bone homeostasis in an intact animal, but inhibitor studies in vitro remain promising.

\section{Mechanistic Role of TRAP in Bone Resorption}

\section{TRAP as a Phosphoprotein Phosphatase}

The bone matrix phosphoprotein, osteopontin, has been shown to bind to osteoclast cell surface integrins via an RGD motif, thereby mediating substrate adhesion, at least in vitro. ${ }^{36}$ EkRylander et al. ${ }^{31}$ found that osteopontin is a substrate for the phosphoprotein phosphatase activity of osteoclast TRAP in vitro, resulting in dephosphorylation of serine residues. Other phosphatase enzymes, including alkaline phosphatase and prostatic acid phosphatase, lacked this enzymic activity. Following dephosphorylation of osteopontin by TRAP, it was no longer able to support osteoclast-substrate binding ${ }^{31}$ suggesting that TRAP could regulate osteoclast adhesion to the bone surface. This effect would not necessarily inhibit resorption; detachment could permit osteoclasts to migrate across the bone surface to new resorptive sites. Osteopontin is itself an osteoclast product secreted into the resorption space $7,26,60,83,118$ and is also a potent inhibitor of de novo hydroxyapatite nucleation and crystal growth. Dephosphorylation of osteopontin also abolishes this inhibitory effect, ${ }^{13,55}$ although the consequences of this activity for resorption are unclear. The major matrix protein, osteonectin, is also a TRAP substrate, ${ }^{4}$ so the major function of TRAP in resorption may simply be the catabolic degradation of bone matrix phosphoproteins, thereby aiding access by specific proteinases. This is similar to the function proposed for TRAP in the degradation of red cell membrane and cytoskeletal phosphoproteins during erythrophagocytosis by macrophages. ${ }^{107}$

\section{Other Possible Functions of TRAP Enzymes}

An alternative, but not mutually exclusive, model for TRAP function in bone resorption is based on the observation that the enzyme is able to catalyze the generation of reactive oxygen species (ROS). Because TRAP in its native reduced form has an $\mathrm{Fe}$ (III)-Fe(II) active site, the ferrous ion is able to act as an electron donor. The relevant reactions involved in the generation of ROS, known as Haber-Weiss-Fenton chemistry, are shown as follows:

\section{Hydroxyl radical formation:}

$$
\begin{aligned}
\text { TRAP-Fe(III)-Fe(II) } & +\mathrm{H}_{2} \mathrm{O}_{2}{ }^{\prime} \text { TRAP-Fe(III)-Fe(III) } \\
+ & \mathrm{OH}^{\cdot}+\mathrm{OH}^{-}
\end{aligned}
$$

\section{TRAP regeneration:}

$$
\text { TRAP-Fe(III)-Fe(III) }+\mathrm{O}_{2}^{-} \text {, TRAP-Fe(III)-Fe(II) }+\mathrm{O}_{2}
$$

Osteoclasts possess the same NADPH-oxidase-dependent superoxide-generating system utilized by macrophages and granulocytes to generate free radicals for microbial killing. ${ }^{13,114}$ There is clear evidence that oxygen free radicals are produced at the resorptive interface with bone and are required for active resorption. ${ }^{23,40,65,97}$ The potential activity of TRAP as a Fenton catalyst was recognized in studies of the porcine enzyme..$^{11}$ Hayman et al. ${ }^{51}$ demonstrated that recombinant human TRAP is able to catalyze iron-dependent peroxidation of luminol, which can be monitored as chemiluminescence, independent of phosphatase activity. Similarly, Halleen et al. ${ }^{46}$ reported that RAW264 macrophages overexpressing TRAP produced reactive oxygen metabolites. More recently, this group reported that ROS can be targeted to destroy collagen and other proteins in resorbing osteoclasts. TRAP was found in transcytotic vesicles transporting matrix degradation products through the cell. ${ }^{47}$ This suggests that TRAP-generated ROS can participate in bone matrix degradation not only in resorption lacunae but also intracellularly in transcytotic vesicles. This mechanism could be important in tissue remodeling and as an adjunct defense mechanism in TRAP-expressing phagocytic cells. ${ }^{47}$

As noted earlier, the purified porcine enzyme is irreversibly inhibited when treated with hydrogen peroxide in the presence of ascorbate. The Fe(III)-Zn(II) derivative of the enzyme was stable under the same conditions. The results are consistent with the generation of hydroxyl radicals by the enzyme, and subsequent inactivation as a result of reaction of the hydroxyl radicals with active-site residues. ${ }^{9}$ The presence of the inactive form of TRAP in the circulation (see earlier) could be indirect evidence that a strong oxidative environment occurs during bone resorption in vivo and may also suggest a simple mechanism of feedback regulation of TRAP enzyme activity by product inhibition.

Among its range of established substrates, TRAP has long been known to be capable of hydrolyzing pyrophosphate. ${ }^{37}$ Pyrophosphate is a known inhibitor of bone resorption, ${ }^{108}$ so pyrophosphate activity of TRAP per se could lead to an increase in bone resorption by osteoclasts. The bisphosphonates are a class of antiosteoporotic drugs with structures analogous to pyrophosphate; the P-O-P structure is replaced by a nonhydrolyzable P-C-P. In principle, the bisphosphonates could act as substrate analog TRAP inhibitors, but etidronate, a commonly used bisphosphonate, is a relatively poor inhibitor of TRAP. ${ }^{2} \mathrm{We}$ also found no correlation between biological activity of bisphosphonates and TRAP-inhibitory activity (unpublished observations). Bisphosphonates act more globally on osteoclast viability. Nitrogen-containing bisphosphonates, such as alendronate, iban- 
dronate, and risedronate, inhibit posttranslational prenylation of Ras in osteoclasts, which leads to apoptosis. ${ }^{78}$ In the case of alendronate at least this results from the inhibition of an unidentified enzyme involved in the conversion of mevalonate to geranylgeranyldiphosphate, the substrate for prenylation of most GTP binding proteins. ${ }^{33}$

\section{Directions for Future Research}

Mammalian TRAP is clearly expressed at very high levels in osteoclasts via the use of a separate conserved promoter. Teleologically, it is difficult to believe that such specific expression lacks a purpose. Transgenic mice, both knockouts and overexpressed, indicate that TRAP can be limiting for resorption. The full extent of this role is probably masked by the ability of the bone synthetic pathways to compensate for deficient resorption, an observation that is hardly surprising given the tight homeostatic control of serum calcium. Greater insight may come from subjecting the animals to stresses such as ovariectomy or calcium loading, or by crossing them to other stains that have altered bone metabolism (e.g., op/op) or lower intrinsic bone mineral density (e.g., C57BL/6). Ongoing studies of the active site of plant and mammalian TRAP enzymes, and identification of high-affinity substrates and inhibitors, suggest that active-site antagonists are possible and might be candidate antiosteoporotic drugs.

\section{References}

1. Alcantara, O., Reddy, S., Roodman, G., and Boldt, D. Transcriptional regulation of the tartrate-resistant acid phosphatase gene (TRAP) gene by iron. Biochem J 298:421-425; 1994.

2. Allen, S. H., Nuttleman, P. R., Ketcham, C. M., and Roberts, R. M. Purification and characterization of human tartrate-resistant acid phosphatase. J Bone Miner Res 4:47-55; 1989.

3. Anderson, T. R. and Toverud, S. U. Purification and characterization of purple acid phosphatase from developing rat bone. Arch Biochem Biophys 247:131$139 ; 1986$.

4. Andersson, G. and Ek-Rylander, B. The tartrate-resistant purple acid phosphatase of bone osteoclasts-A protein phosphatase with multivalent substrate specificity and regulation. Acta Orthopaed Scand 66:189-194; 1995.

5. Angel, N. Z., Walsh, N., Forwood, M. R., Ostrowski, M. C., Cassady, A. I., and Hume, D. A. Transgenic mice overexpressing tartrate-resistant acid phosphatase exhibit an increased rate of bone turnover. J Bone Miner Res $15: 103-110 ; 2000$.

6. Aquino, M. A. S., Lim, J. S., and Sykes, A. G. Mechanism of the reaction of different phosphates with the iron(II)iron(III) form of purple acid phosphatase from porcine uteri (uteroferrin). J Chem Soc Dalton Trans 21:429-436; 1994

7. Arai, N., Ohya, K., and Ogura, H. Osteopontin mRNA expression during bone resorption: An in situ hybridization study of induced ectopic bone in the rat. Bone Miner 22:129-145; 1993.

8. Baumbach, G. A., Saunders, P. T., Ketcham, C. M., Bazer, F. W., and Roberts, R. M. Uteroferrin contains complex and high mannose-type oligosaccharides when synthesized $n$ vitro. Mol Cell Biochem 105:107-117; 1991.

9. Beck, J. L., Durack, M. C., Hamilton, S. E., and de Jersey, J. Irreversible inactivation of purple acid phosphatase by hydrogen peroxide and ascorbate. J Inorg Biochem 73:245-252; 1999.

10. Beck, J. L., Keough, D. T., De Jersey, J., and Zerner, B. Enzymatically active zinc, copper and mercury derivatives of the one-iron form of pig allantoic fluid acid phosphatase. Biochim Biophys Acta 791:357-363; 1984.

11. Beedles, K. E., Sharpe, P. T., Wagner, E. F., and Grigoriadis, A. E. A putative role for c-Fos in the pathophysiology of Paget's disease. J Bone Miner Res 14(Suppl. 2):21-28; 1999.

12. Boldt, D. H., Reddy, S. V. J., Craig, F., Alcantara, O., and Roodman, G. D. Transcriptional regulation of the tartrate resistant acid phosphatase (TRAP) gene by iron. Blood 80(Suppl.):718; 1992.

13. Boskey, A. L., Maresca, M., Ullrich, W., Doty, S. B., Butler, W. T., and Prince, C. W. Osteopontin-hydroxyapatite interactions in vitro-Inhibition of hydroxyapatite formation and growth in a gelatin-gel. Bone Miner 22:147$159 ; 1993$.
14. Boyce, B. F., Wright, K., Reddy, S. V., Koop, B. A., Story, B., Devlin, R., Leach, R. J., Roodman, G. D., and Windle, J. J. Targeting simian virus $40 \mathrm{~T}$ antigen to the osteoclast in transgenic mice causes osteoclast tumors and transformation and apoptosis of osteoclasts. Endocrinology 136:5751-5759; 1995.

15. Brehme, C. S., Roman, S., Shaffer, J., and Wolfert, R. Tartrate-resistant acid phosphatase forms complexes with $\alpha 2$-macroglobulin in serum. J Bone Miner Res 14:311-318; 1999.

16. Bresciani, R. and Von Figura, K. Dephosphorylation of the mannose-6phosphate recognition marker is localized in later compartments of the endocytic route. Identification of purple acid phosphatase (uteroferrin) as the candidate phosphatase. Eur J Biochem 238:669-674; 1996.

17. Buhi, W. C., Ducsay, C. A., Bazer, F. W., and Roberts, R. M. Iron transfer between the purple phosphatase uteroferrin and transferrin and its possible role in iron metabolism of the fetal pig. J Biol Chem 257:1712-1723; 1982.

18. Campbell, H. D., Dionysius, D. A., Keough, D. T., Wilson, B. E., de Jersey, J., and Zerner, B. Iron-containing acid phosphatases: Comparison of the enzymes from beef spleen and pig allantoic fluid. Biochem Biophys Res Commun 82:615-620; 1978.

19. Cassady, A. I., King, A. G., Cross, N. C., and Hume, D. A. Isolation and characterization of the genes encoding mouse and human type-5 acid phosphatase. Gene 130:201-207; 1993.

20. Chamberlain, P., Compston, J., Cox, T. M., Hayman, A. R., Imrie, R. C., Reynolds, K., and Holmes, S. D. Generation and characterization of monoclonal antibodies to human type-5 tartrate-resistant acid phosphatase: Development of a specific immunoassay of the isoenzyme in serum. Clin Chem 41:1495-1499; 1995.

21. Chen, T. T., Bazer, F. W., Cetorelli, J. J., Pollard, W. E., and Roberts, R. M Purification and properties of a progesterone induced basic glycoprotein from the uterine fluid of pigs. J Biol Chem 248:8560-8566; 1973.

22. Crans, D. C., Simone, C. M., Holz, R. C., and Que, L., Jr. Interaction of porcine uterine fluid purple acid phosphatase with vanadate and vanadyl cation. Biochemistry 31:11731-11739; 1992.

23. Darden, A. G., Ries, W. L., Wolf, W. C., Rodriguiz, R. M., and Key, L. L., Jr. Osteoclastic superoxide production and bone resorption: Stimulation and inhibition by modulators of NADPH oxidase. J Bone Miner Res 11:671-675; 1996.

24. Davis, J. C., Lin, S. S., and Averill, B. A. Kinetics and optical spectroscopic studies on the purple acid phosphatase from beef spleen. Biochemistry 20:4062-4067; 1981.

25. del Pozo, J. C., Allona, I., Rubio, V., Leyva, A., de la Peña, A., Aragoncillo, C., and Paz-Ares, J. A type 5 acid phosphatase gene from Aribodopsis thaliana is induced by phosphate starvation and by some other types of phosphate mobilising/oxidative stress conditions. Plant J 19:579-589; 1999.

26. Dodds, R. A., Connor, J. R., James, I. E., Rykaczewski, E. L., Appelbaum, E., Dul, E., and Gowen, M. Human osteoclasts, not osteoblasts, deposit osteopontin onto resorption surfaces-An in vitro and ex vivo study of remodeling bone. J Bone Miner Res 10:1666-1680; 1995.

27. Echetebu, Z. O., Cox, T. M., and Moss, D. W. Antibodies to porcine uteroferrin used in measurement of human tartrate-resistant acid phosphatase. Clin Chem 33:1832-1836; 1987.

28. Efstratiadis, T. and Moss, D. W. Tartrate-resistant acid phosphatase of human lung. Enzyme 33:34-40; 1985.

29. Ek-Rylander, B., Barkhem, T., Ljusberg, J., Ohman, L., Andersson, K. K., and Andersson, G. Comparative studies of rat recombinant purple acid phosphatase and bone tartrate-resistant acid phosphatase. Biochem J 321:305-311; 1997.

30. Ek-Rylander, B., Bill, P., Norgård, M., Nilsson, S., and Andersson, G. Cloning, sequence and development expression of a type 5 tartrate-resistant, acid phosphatase of rat bone. J Biol Chem 266:24684-24689; 1991.

31. Ek-Rylander, B., Flores, M., Wendel, M., Heinegård, D., and Andersson, G. Dephosphorylation of osteopontin and bone sialoprotein by osteoclastic tartrate-resistant acid phosphatase. J Biol Chem 269:14853-14856; 1994.

32. Fallon, M. I. D. Bone resorbing fluid from osteoblasts is acidic-An in vitro micropuncture study. In: Cohn, D. V., Fijita, T., Potts, J. T. J., and Talmage, R. V., Eds. Endocrine Control of Bone and Cartilage Metabolism. Amsterdam: Elsevier; 1984; 144-146.

33. Fisher, J. E., Rogers, M. J., Halasy, J. M., Luckman, S. P., Hughes, D. E., Masarachia, P. J., Wesolowski, G., Russell, R. G., Rodan, G. A., and Reszka, A. A. Alendronate mechanism of action: Geranylgeraniol, an intermediate in the mevalonate pathway, prevents inhibition of osteoclast formation, bone resorption, and kinase activation in vitro. Proc Natl Acad Sci USA 96:133$138 ; 1999$. 
34. Fleckenstein, E. and Drexler, H. G. Tartrate-resistant acid phosphatase: Gene structure and function. Leukemia 11:10-13; 1997.

35. Fleckenstein, E. C., Dirks, W. G., and Drexler, H. G. The human tartrateresistant acid phosphatase (TRAP): Involvement of the hemin responsive elements (HRE) in transcriptional regulation. Leuk Lymphoma 36:603-612; 2000.

36. Flores, M. E., Norgård, M., Heinegård, D., Reinholt, F. P., and Andersson, G. RGD-directed attachment of isolated rat osteoclasts to osteopontin, bone sialoprotein, and fibronectin. Exp Cell Res 201:526-530; 1992.

37. Glomset, J. A. The further purification and properties of a phosphatase from spleen able to hydrolyse completely the phosphorus of $\alpha$-casein. Biochem Biophys Acta 32:349-357; 1959.

38. Grimes, R., Reddy, S. V., Leach, R. J., Scarcez, T., Roodman, G. D. Sakaguchi, A. Y., Lalley, P. A., and Windle, J. J. Assignment of the mouse tartrate-resistant acid phosphatase gene (Acp5) to chromosome 9. Genomics $15: 421-422 ; 1993$

39. Guddat, L. W., McAlpine, A. S., Hume, D., Hamilton, S., de Jersey, J., and Martin, J. L. Crystal structure of mammalian purple acid phosphatase. Struct Fold Des 7:757-767; 1999.

40. Hall, T. J., Schaeublin, M., Jeker, H., Fuller, K., and Chambers, T. J. The role of reactive oxygen intermediates in osteoclastic bone resorption. Biochem Biophys Res Commun 207:280-287; 1995.

41. Halleen, J., Hentunen, T. A., Hellman, J., and Väänänen, H. K. Tartrateresistant acid phosphatase from human bone: Purification and development of an immunoassay. J Bone Miner Res 11:1444-1452; 1996.

42. Halleen, J. M., Alatalo, S. L., Suominen, H., Cheng, S., Janckila, A. J., and Väänänen, H. K. Tartrate-resistant acid phosphatase 5b: A novel serum marker of bone resorption. J Bone Miner Res 15:1337-1345; 2000

43. Halleen, J. M., Hentunen, T. A., Karp, M., Kakonen, S. M., Pettersson, K., and Väänänen, H. K. Characterization of serum tartrate-resistant acid phosphatase and development of a direct two-site immunoassay. J Bone Miner Res 13:683-687; 1998.

44. Halleen, J. M., Kaija, H., Stepan, J. J., Vihko, P., and Väänänen, H. K. Studies on the protein tyrosine phosphatase activity of tartrate-resistant acid phosphatase. Arch Biochem Biophys 352:97-102; 1988

45. Halleen, J. M., Karp, M., Viloma, S., Laaksonen, P., Hellman, J. Kakonen, S. M., Stepan, J. J., Holmes, S., Väänänen, H. K., and Pettersson, K. Two-site immunoassays for osteoclastic tartrate-resistant acid phosphatase based on characterization of six monoclonal antibodies. J Bone Miner Res 14:464$469 ; 1999$

46. Halleen, J. M., Raisanen, S., Salo, J. J., Reddy, S. V., Roodman, G. D. Hentunen, T. A. Lehenkari, P. P., Kaija, H., Vihko, P., and Väänänen, H. K Intracellular fragmentation degradation products by reactive oxygen products generated by tartrate-resistant acid phosphatase in osteoclasts during bone resorption. Bone 23(Suppl.):S341; 1998.

47. Halleen, J. M., Raisanen, S., Salo, J. J., Reddy, S. V., Roodman, G. D. Hentunen, T. A., Lehenkari, P. P., Kaija, H., Vihko, P., and Väänänen, H. K. Intracellular fragmentation of bone resorption products by reactive oxygen species generated by osteoclastic tartrate-resistant acid phosphatase. J Bio Chem 274:22907-22910; 1999.

48. Hannon, R., Blumsohn, A., Naylor, K., and Eastell, R. Response of biochemical markers of bone turnover to hormone replacement therapy: Impact of biological variability. J Bone Miner Res 13:1124-1133; 1998.

49. Hara, A., Sawada, H., Kato, T., Nakayama, T., Yamamoto, H., and Matsumoto, Y. Purification and characterization of a purple acid phosphatase from rat spleen. J Biochem (Tokyo) 95:67-74; 1984.

50. Hayman, A. R., Bune, A. J., Bradley, J. R., Rashbass, J., and Cox, T. M. Osteoclastic tartrate-resistant acid phosphatase (Acp 5): Its localization to dendritic cells and diverse murine tissues. J Histochem Cytochem 48:219228; 2000.

51. Hayman, A. R. and Cox, T. M. Purple acid phosphatase of the human macrophage and osteoclast. Characterization, molecular properties, and crystallization of the recombinant di-iron-oxo protein secreted by baculovirusinfected insect cells. J Biol Chem 269:1294-1300; 1994.

52. Hayman, A. R., Jones, S. J., Boyde, A., Foster, D., Colledge, W. H., Carlton, M. B., Evans, M. J., and Cox, T. M. Mice lacking tartrate-resistant acid phosphatase (Acp 5) have disrupted endochondral ossification and mild osteopetrosis. Development 122:3151-3162; 1996.

53. Hayman, A. R., Warburton, M. J., Pringle, J. A. S., Coles, B., and Chambers, T. J. Purification and characterization of a tartrate-resistant acid phosphatase from human osteoclastoma. Biochem J 261:601-609; 1989.

54. Hentunen, T. A., Reddy, S. V., Boyce, B. F., Devlin, R., Park, H. R., Chung, H., Selander, K. S., Dallas, M., Kurihara, N., Galson, D. L., Goldring, S. R.,
Koop, B. A., Windle, J. J., and Roodman, G. D. Immortalization of osteoclast precursors by targeting Bcl-XL and Simian virus 40 large $\mathrm{T}$ antigen to the osteoclast lineage in transgenic mice. J Clin Invest 102:88-97; 1998.

55. Hunter, G. K., Kyle, C. L., and Goldberg, H. A. Modulation of crystal formation by bone phosphoproteins: Structural specificity of the osteopontinmediated inhibition of hydroxyapatite formation. Biochem J 300:723-728; 1994

56. Inoue, M., Yoshida, H., and Akisaka, T. Visualization of acidic compartment in cultured osteoclasts by use of an acidotrophic amine as a marker for low pH. Cell Tissue Res 298:527-537; 1999.

57. Janckila, A. J., Walton, S. P., and Yam, L. T. Species specificity of monoclonal antibodies to human tartrate-resistant acid phosphatase. Biotechnol Histochem 73:316-324; 1998 .

58. Jemtland, R., Lee, K., and Segre, G. V. Heterogeneity among cells that express osteoclast-associated genes in developing bone. Endocrinology 139: $340-349 ; 1998$

59. Kaija, H., Jia, J., Lindqvist, Y., Andersson, G., and Vihko, P. Tartrateresistant bone acid phosphatase: Large-scale production and purification of the recombinant enzyme, characterization, and crystallization. J Bone Miner Res 14:424-430; 1999.

60. Kaji, H., Sugimoto, T., Miyauchi, A., Fukase, M., Tezuka, K., Hakeda, Y., Kumegawa, M., and Chihara, K. Calcitonin inhibits osteopontin mRNA expression in isolated rabbit osteoclasts. Endocrinology 135:484-487; 1994

61. Keough, D. T., Beck, J. L., de Jersey, J., and Zerner, B. Iron-containing acid phosphatases: Interaction of phosphate with the enzyme from pig allantoic fluid. Biochem Biophys Res Commun 108:1643-1684; 1982

62. Keough, D. T., Dionysius, D. A., de Jersey, J., and Zerner, B. Iron-containing acid phosphatases: Characterization of the metal-ion binding site of the enzyme from pig allantoic fluid. Biochem Biophys Res Commun 94:600$605 ; 1980$.

63. Ketcham, C. M., Baumbach, G. A., Bazer, F. W., and Roberts, R. M. The type 5 acid phosphatase from spleen of humans with hairy cell leukemia. J Biol Chem 260:5768-5776; 1985 .

64. Ketcham, C. M., Roberts, R. M., Simmen, R. C. M., and Nick, H. S Molecular cloning of the type 5, iron-containing, tartrate-resistant acid phosphatase from human placenta. J Biol Chem 264:557-563; 1989.

65. Key, L. L., Jr, Ries, W. L., Taylor, R. G., Hays, B. D., and Pitzer, B. L. Oxygen derived free radicals in osteoclasts: The specificity and location of the nitroblue tetrazolium reaction. Bone 11:115-119; 1990

66. Klabunde, T., Strater, N., Frohlich, R., Witzel, H., and Krebs, B. Mechanism of $\mathrm{Fe}(\mathrm{III})-\mathrm{Zn}$ (II) purple acid phosphatase based on crystal structures. J Mol Biol 259:737-748; 1996

67. Klabunde, T., Strater, N., Krebs, B., and Witzel, H. Structural relationship between the mammalian $\mathrm{Fe}$ (III)-Fe(II) and the $\mathrm{Fe}$ (III)-Zn(II) plant purple acid phosphatases. FEBS Lett 367:56-60; 1995.

68. Lam, K. W., Li, C. Y., Yam, L. T., and Desnick, R. J. Comparison of the tartrate-resistant acid phosphatase in Gaucher's disease and leukemic reticuloendotheliosis. Clin Biochem 14:177-181; 1981.

69. Lam, K. W., Eastlund, D. T., Li, C. Y., and Yam, L. T. Biochemical properties of tartrate-resistant acid phosphatase in serum of adults and children. Clin Chem 24:1105-1108; 1978.

70. Leach, R. J., Reus, B. E., Hundley, J. E., Johnson-Pais, T. L., and Windle, J. J. Confirmation of the assignment of the human tartrate-resistant acid phosphatase gene (ACP5) to chromosome 19. Genomics 19:180-181; 1994

71. LeBansky, B. R., McKnight, T., and Griffing, L. R. Purification and characterization of a secreted purple phosphatase from soybean suspension culture. Plant Physiol 99:391-395; 1992.

72. Li, Y. P. and Chen, W. Characterization of mouse cathepsin K gene, the gene promoter, and the gene expression. J Bone Miner Res 14:487-499; 1999

73. Li, Y. P., Chen, W., Liang, Y., Li, E., and Stashenko, P. Atp6i-deficient mice exhibit severe osteopetrosis due to loss of osteoclast-mediated extracellular acidification. Nature Genet 23:447-451; 1999.

74. Ling, P. and Roberts, R. M. Uteroferrin and intracellular tartrate-resistant acid phosphatases are the products of the same gene. J Biol Chem 268:6896-6902; 1993

75. Ljusberg, J., Ek-Rylander, B., and Andersson, G. Tartrate-resistant purple acid phosphatase is synthesized as a latent proenzyme and activated by cysteine proteinases. Biochem J 343:63-69; 1999.

76. Lord, D. K., Cross, N. C., Bevilacqua, M. A., Rider, S. H., Gorman, P. A., Groves, A. V., Moss, D. W., Sheer, D., and Cox, T. M. Type 5 acid phosphatase. Sequence, expression and chromosomal localization of a differentiation-associated protein of the human macrophage. Eur J Biochem 189: $287-293 ; 1990$ 
77. Luchin, A., Purdom, G., Murphy, K., Clark, M.-Y., Angel, N. Z., Cassady, A. I., Hume, D. A., and Ostrowski, M. C. The microphthalmia transcription factor regulates expression of the tartrate-resistant acid phosphatase gene during terminal differentiation of osteoclasts. J Bone Miner Res 15:451-460; 2000.

78. Luckman, S. P., Hughes, D. E., Coxon, F. P., Graham, R., Russell, G., and Rogers, M. J. Nitrogen-containing bisphosphonates inhibit the mevalonate pathway and prevent post-translational prenylation of GTP-binding proteins, including Ras. J Bone Miner Res 13:581-589; 1998.

79. Manolagas, S. C. The role of IL-6 type cytokines and their receptors in bone Ann NY Acad Sci 840:194-204; 1998

80. Marshall, K., Nash, K., Haussman, G., Cassady, I., Hume, D., de Jersey, J., and Hamilton, S. Recombinant human and mouse purple acid phosphatases: Expression and characterization. Arch Biochem Biophys 345:230-236; 1997.

81. Merkx, M. and Averill, B. A. Probing the role of the trivalent metal in phosphate ester hydrolysis: preparation and characterization of purple acid phosphatases containing $\mathrm{Al}(\mathrm{III}) \mathrm{Zn}$ (II) and In(III)Zn(II) active sites, including the first example of an active aluminum enzyme. J Am Chem Soc 121:66836689; 1999.

82. Merkx, M., Pinkse, M. W., and Averill, B. A. Evidence for nonbridged coordination of p-nitrophenyl phosphate to the dinuclear Fe(III)-M(II) center in bovine spleen purple acid phosphatase during enzymatic turnover. Biochemistry 38:9914-9925; 1999.

83. Merry, K., Dodds, R., Littlewood, A., and Gowen, M. Expression of osteopontin mRNA by osteoclasts and osteoblasts in modeling adult human bone. J Cell Sci 104:1013-1020; 1993.

84. Moonga, B. S., Moss, D. W., Patchell, A., and Zaidi, M. Intracellular regulation of enzyme secretion from rat osteoclasts and evidence for a functional role in bone resorption. J Physiol 429:29-45; 1990.

85. Nakazato, H., Okamoto, T., Nishikoori, M., Washio, K., Morita, N., Haraguchi, K., Thompson, G. A., Jr, and Okuyama, H. The glycosylphosphatidylinositol-anchored phosphatase from Spirodela oligorrhiza is a purple acid phosphatase. Plant Physiol 118:1015-1020; 1998.

86. Nash, K., Feldmuller, M., de Jersey, J., Alewood, P., and Hamilton, S Continuous and discontinuous assays for phosphotyrosyl protein phosphatase activity using phosphotyrosyl peptide substrates. Anal Biochem 213:303-309; 1993.

87. Nordahl, J., Andersson, G., and Reinholt, F. P. Chondroclasts and osteoclasts in bones of young rats: Comparison of ultrastructural and functional features. Calcif Tissue Int 63:401-408; 1998

88. Ohno, J., Fukuyama, K., Hara, A., and Epstein, W. L. Immuno- and enzymehistochemical detection of phosphoprotein phosphatase in rat epidermis. J Histochem Cytochem 37:629-634; 1989.

89. Orlando, J. L., Zirino, T., Quirk, B. J., and Averill, B. A. Purification and properties of the native form of the purple acid phosphatase from bovine spleen. Biochemistry 32:8120-8129; 1993.

90. Reddy, M. A., Yang, B. S., Yue, X., Barnett, C. J., Ross, I. L., Sweet, M. J., Hume, D. A., and Ostrowski, M. C. Opposing actions of c-ets/PU.1 and c-myb protooncogene products in regulating the macrophage-specific promoters of the human and mouse colony-stimulating factor-1 receptor (c-fms) genes. J Exp Med 180:2309-2319; 1994.

91. Reddy, S. V., Alcantara, O., and Boldt, D. H. Analysis of DNA binding proteins associated with hemin-induced transcriptional inhibition. The hemin response element binding protein is heterogeneous complex that includes the Ku protein. Blood 91:1793-1801; 1998.

92. Reddy, S. V., Hundley, J. E., Windle, J. J., Alcantara, O., Linn, R., Leach, R. J., Boldt, D. H., and Roodman, G. D. Characterization of the mouse tartrate-resistant acid phosphatase (TRAP) gene promoter. J Bone Miner Res 10:601-606; 1995.

93. Reddy, S. V., Hundley, J. E., Windle, J. J., Leach, R. J., Alcantara, O., Boldt, D. H., and Roodman, G. D. The mouse tartrate-resistant acid phosphatase gene (TRAP) contains two active promoters and is regulated by iron. Clin Res 42:210; 1994

94. Reddy, S. V., Kuzhandaivelu, N., Acosta, L. G., and Roodman, G. D. Characterization of the $5^{\prime}$-flanking region of the human tartrate-resistant acid phosphatase (TRAP) gene. Bone 16:587-593; 1995.

95. Reddy, S. V., Scarcez, T., Windle, J. J., Leach, R. J., Hundley, J. E., Chirgwin, J. M., Chou, J. Y., and Roodman, G. D. Cloning and characterization of the $5^{\prime}$-flanking region of the mouse tartrate-resistant acid phosphatase gene. J Bone Miner Res 8:1263-1270; 1993.

96. Reilly, T. J., Baron, G. S., Nano, F. E., and Kuhlenschmidt, M. S. Characterization and sequencing of a respiratory burst-inhibiting acid phosphatase from Francisella tularensis. J Biol Chem 271:10973-10983; 1996.
97. Ries, W. L., Key, L. L., Jr, and Rodriguiz, R. M. Nitroblue tetrazolium reduction and bone resorption by osteoclasts in vitro inhibited by a manganese-based superoxide dismutase mimic. J Bone Miner Res 7:931-939; 1992.

98. Roberts, R. M., Baumbach, G. A., Saunders, P. T., Raub, T. J., Renegar, R. H., and Bazer, F. W. Possible function of carbohydrate on glycoproteins secreted by the pig uterus during pregnancy. Mol Cell Biochem 72:67-79; 1986.

99. Robinson, D. B. and Glew, R. H. A tartrate-resistant acid phosphatase from Gaucher spleen. J Biol Chem 255:5846-5870; 1980.

100. Ross, I. L., Dunn, T. L., Yue, X., Roy, S., Barnett, C. J., and Hume, D. A. Comparison of the expression and function of the transcription factor PU.1 (Spi-1 proto-oncogene) between murine macrophages and B lymphocytes. Oncogene 9:121-132; 1994.

101. Ross, I. L., Yue, X., Ostrowski, M. C., and Hume, D. A. Interaction between PU.1 and another Ets family transcription factor promotes macrophagespecific basal transcription initiation. J Biol Chem 273:6662-6669; 1998.

102. Saftig, P., Hartmann, D., Lullmann-Rauch, R., Wolff, J., Evers, M., Koster, A., Hetman, M., von Figura, K., and Peters, C. Mice deficient in lysosomal acid phosphatase develop lysosomal storage in the kidney and central nervous system. J Biol Chem 272:18628-18635; 1997.

103. Sakakura, Y., Yajima, T., and Tsuruga, E. Confocal laser scanning microscopic study [corrected] or tartrate-resistant acid phosphatase-positive cells in the dental follicle during early morphogenesis of mouse embryonic molar teeth. Arch Oral Biol 43:353-360; 1998.

104. Sato, M., Morii, E., Takebayashi-Suzuki, K., Yasui, N., Ochi, T., Kitamura, Y., and Nomura, S. Microphthalmia-associated transcription factor interacts with PU.1 and c-fos: Determination of their subcellular localization. Biochem Biophys Res Commun 254:384-387; 1999.

105. Schenk, G., Guddat, L. W., Ge, Y., Carrington, L. E., Hume, D. A., Hamilton, S., and de Jersey, J. Identification of mammalian-like purple acid phosphatases in a wide range of plants. Gene 250:117-125; 2000.

106. Schindelmeiser, J., Munstermann, D., Mayer, B., Holstein, A. F., and Davidoff, M. S. Occurrence of enzymes of free radicals metabolism suggests the possible cytotoxic capacity of the transitional epithelium of the human ureter. Cell Tissue Res 287:351-356; 1997.

107. Schindelmeiser, J., Münstermann, D., and Witzel, H. Histochemical investigations on the localizations of the purple acid phosphatase in the bovine spleen. Histochemistry 87:13-19; 1987.

108. Schlesinger, P. H. and Blair, H. C. Bisphosphonates. In: Rifkin, B. R. and Gay, C. V., Eds. Biology and Physiology of the Osteoclast. Boca Raton, FL: CRC; 1992.

109. Schwartzberg, P. L., Xing, L., Hoffman, O., Lowell, C. A., Garrett, L., Boyce, B. F., and Varmus, H. E. Rescue of osteoclast function by transgenic expression of kinase-deficient $\mathrm{Src}$ in $\mathrm{src}-/-$ mutant mice. Genes Dev 11:2835-2844; 1997.

110. Schwender, C. F., Beers, S. A., Malloy, E., Demarest, K., Minor, L., and Lau, K. 1-naphthylmethylphosphonic acid derivatives as osteoclastic acid phosphatase inhibitors. Bioorg Med Chem Lett 5:1801-1806; 1995.

111. Sibille, J. C., Doi, K., and Aisen, P. Hydroxyl radical formation and ironbinding proteins. Stimulation by the purple acid phosphatases. J Biol Chem 262:59-62; 1987

112. Silver, I. A., Murrills, R. J., and Etherington, D. J. Microelectrode studies on the acid microenvironment beneath adherent macrophages and osteoclasts. Exp Cell Res 175:266-276; 1988.

113. Silverton, S. F., Mesaros, S., Markham, G. D., and Malinski, T. Osteoclast radical interactions: NADPH causes pulsatile release of NO and stimulates superoxide production. Endocrinology 136:5244-5247; 1995.

114. Steinbeck, M. J., Appel, W. H., Jr, Verhoeven, A. J., and Karnovsky, M. J. NADPH-oxidase expression and in situ production of superoxide by osteoclasts actively resorbing bone. J Clin Biol 126:765-772; 1994.

115. Steingrímsson, E., Moore, K. J., Lamoreux, M. L., Ferre-D'Amare, A. R., Burley, S. K., Zimring, D. C. S., Skow, L. C., Hodgkinson, C. A., Arnheiter, H., Copeland, N. G., and Jenkins, N. A. Molecular basis of mouse microphthalmia (mi) mutations helps explain their developmental and phenotypic consequences. Nature Genet 8:256-263; 1994.

116. Strater, N., Klabunde, T., Tucker, P., Witzel, H., and Krebs, B. Crystal structure of a purple acid phosphatase containing a dinuclear Fe(III)-Zn(II) active site. Science 268:1489-1492; 1995.

117. Tondravi, M. M., McKercher, S. R., Anderson, K., Erdmann, J. M., Quiroz, M., Maki, R., and Teitelbaum, S. L. Osteopetrosis in mice lacking haematopoietic transcription factor PU.1. Nature 386:81-84; 1997.

118. Tong, H. S., Sakai, D. D., Sims, S. M., Dixon, S. J., Yamin, M., Goldring, S. R., Snead, M. L., and Minkin, C. Murine osteoclasts and spleen cell 
polykaryons are distinguished by mRNA phenotyping. J Bone Miner Res 9:577-584; 1994.

119. Uppenberg, J., Lindqvist, F., Svensson, C., Ek-Rylander, B., and Andersson, G. Crystal structure of a mammalian purple acid phosphatase. J Mol Biol 290:201-211; 1999

120. Wang, X., Randall, C. R., True, A. E., and Que, L., Jr. X-ray absorption spectroscopic studies of the FeZn derivative of uteroferrin. Biochemistry $35: 13946-13954 ; 1996$.

121. Weilbacher, K. N., Hershey, C. L., Takemoto, C. M. Horstmann, M. A., Hemesath, T. J., Tashjian, A. H., and Fisher, D. E. Age-resolving osteopetrosis: A rat model implicating microphthalmia and the related transcription factor TFE3. J Exp Med 187:775-785; 1998
122. Wynne, C. J., Hamilton, S. E., Dionysius, D. A., Beck, J. L., and de Jersey, J. Studies on the catalytic mechanism of pig purple acid phosphatase. Arch Biochem Biophys 319:133-141; 1995.

123. Zaidi, M., Moonga, B., Moss, D. W., and MacIntyre, I. Inhibition of osteoclastic acid phosphatase abolishes bone resorption. Biochem Biophys Res Commun 159:68-71; 1989.

Date Received: December 13, 1999

Date Revised: July 3, 2000

Date Accepted: July 3, 2000 